\section{ANÁLISE DAS COMUNIDADES DE PESQUISADORES BRASILEIROS QUE ATUAM NA ÁREA DA FILOSOFIA: um estudo a partir da justaposição entre os dados da Plataforma Lattes e Web of Science (2007-20 I6)}

Fábio Mascarenhas Silva* María Luisa Lascurain Sánchez** Antonio Eleazar Serrano López $z^{* * * *}$ Elías Sanz Casado ${ }^{* * * *}$
RESUMO Analisa se há diferentes populações de pesquisadores brasileiros da Filosofia na justaposição entre os registros das bases Plataforma Lattes (PL) e Web of Science (WoS) no que respeita aos hábitos de publicação. $O$ universo contemplou 6.060 currículos de pesquisadores atuantes na Filosofia, dos quais se extraíram 43.345 artigos publicados entre 2007 a 2016, desses, 1.657 estão indexados na WoS. Os dados da PL foram extraídos com o ScriptLattes. Utilizaram-se pacotes em linguagem de programação $R$ para identificar os idiomas dos artigos e as temáticas (técnica de "Topic Modeling"). Para gerar grafos de coautoria adotou-se o Gephi. Este estudo identificou duas populações distintas: uma que atua e produz majoritariamente na Filosofia ou temas afins às Ciências Humanas e Sociais (a maioria dos currículos) e outra cuja atuação e produção científica estão centradas nas Ciências da Vida (os currículos da justaposição), porém com traços interdisciplinares concentrados em estudos bioéticos e epistemológicos. Os resultados indicam uma produtividade média maior na segunda metade da década para ambas as bases. O idioma português prevalece na $\mathrm{PL}$ com $89 \%$, enquanto a língua inglesa domina na WoS com 75,72\%. O núcleo de periódicos da PL concentra-se na área da Filosofia enquanto na WoS predominam as Ciências da vida, o mesmo ocorre nos mapas temáticos. Há compatibilidade entre os mapas de tópicos temáticos e os grafos de coautorias, sugerindo boa representação das comunidades analisadas. Conclui-se que a metodologia de justaposição de dados torna visível padrões subjacentes de hábitos de publicação, imperceptíveis nas estratégias metodológicas tradicionais.

Palavras-chave: Indicadores bibliométricos. Pesquisadores brasileiros da Filosofia. Hábitos de publicação. Ciências Humanas.
* Doutor em Ciência da Informação pela Universidade de São Paulo, Brasil. Professor Associado da Universidade Federal de Pernambuco, Brasil. Docente permanente do Programa de Pós-Graduação em Ciência da Informação da Universidade Federal de Pernambuco, Brasil.

E-mail: fabiomascarenhas@gmail.com.

** Doutora em Comunicação pela Universidade Carlos III de Madri, Espanha. Professora do Departamento de Biblioteconomia e Documentação da Universidade Carlos III de Madri, Espanha. Membro do Laboratório de Estudos Métricos de Informação da Universidade Carlos III de Madri, Espanha.

E-mail: mlascura@bib.uc3m.es.

*** Doutor em Documentação pela Universidade Carlos III de Madrid, Espanha. Professor visitante na Universidade Carlos III de Madri, Espanha.

E-mail: aeserran@bib.uc3m.es.

***** Doutor em Ciências Biológicas pela Universidade Complutense de Madri, Espanha. Catedrático de Biblioteconomia e Documentação da Universidade Carlos III de Madri, Espanha. Diretor do Laboratório de Estudos Métricos da Informação da Universidade Carlos III de Madri, Espanha.

E-mail: elias@bib.uc3m.es. 


\section{INTRODUÇÃO}

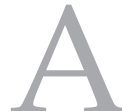

produção científica brasileira da área de Humanidades é um profícuo campo para investigações bibliométricas devido a baixa incidência de estudos sobre a mesma. Do ponto de vista da gestão em Ciência, Tecnologia e Inovação (CT\&I), tais estudos podem contribuir para minimizar as assimetrias nos processos avaliativos nas instâncias das políticas científicas, das quais as Humanidades têm sido desfavorecidas. As assimetrias sobressaem-se em modelos avaliativos balizados por índices de bases de dados internacionais como a Web of Science (WoS) e Scopus. É de amplo conhecimento que as Ciências Sociais e Humanas são desprestigiadas nessas bases, quadro que se agrava para os países de língua não inglesa. Assim, identificar e ressaltar as particularidades da produção das humanidades é também uma questão de equilíbrio de forças.

Motivados por melhor compreender a produção científica brasileira em humanidades, em especial quanto aos hábitos de produção, considera-se importante pensar em estratégias metodológicas a conjuntura científica em nível nacional sem, no entanto, olvidar de um panorama internacional. Destarte, esse estudo baseia-se na justaposição entre uma fonte de dados brasileira, a Plataforma Lattes, e outra internacional, a Web of Science (Wos). Ou seja, em análises pautadas em dados coincidentes entre ambas as fontes de informação.

O uso da Plataforma Lattes atenua um dos problemas ressaltados por Iribarren-Maestro, Lascurain-Sánchez, e Sanz-Casado (2009) quanto a limitação das bases de dados em relação a cobertura das humanidades. Para os autores, esforços têm sido empreendidos no ensejo de implantar estratégias minimizadoras desse problema, dentre as quais o desenvolvimento de fontes de dados específicas, como bases de dados nacionais criadas especialmente para esses grupos.

Dentre as vantagens de utilizar a Plataforma Lattes destacam-se: a exaustividade (a produção dos pesquisadores brasileiros está massivamente representada nesta base, mesmo aquelas ausentes em outros índices como a WoS ou Scopus); a diversidade (além dos dados bibliográficos (artigos, livros, capítulos, trabalhos de congresso), constam registros de projetos, produções artísticas, patentes, orientações, participação em comissões julgadores, entre outras); e a atualidade (os currículos são atualizados pelos próprios pesquisadores, que costumam incluir as produções logo que as realizam).

Para uma perspectiva mundial elegeuse a WoS por ser possível identificar a nacionalidade da produção, além da sua amplitude global, ainda que se reconheça que a participação das Ciências Sociais e Humanidades em bases internacionais é sempre reduzida (ARCHAMBAULT; LARIVIERE, 2010).

$\mathrm{Na}$ tabela 1 constam os números de pesquisadores brasileiros em humanidades identificados na Plataforma Lattes conforme critérios apresentados na seção de métodos. O que diferencia os valores é que na segunda coluna constam o total de pesquisadores que afirmaram atuar exclusivamente em uma área.

Tabela 1: Pesquisadores identificados na Plataforma Lattes por grandes áreas

\begin{tabular}{|c|c|c|}
\hline Área & Total & $\begin{array}{c}\text { Total sem } \\
\text { duplicidade }\end{array}$ \\
\hline Artes & 7030 & 7029 \\
\hline Filosofia & 6060 & 6056 \\
\hline Historia & 8243 & 7554 \\
\hline Letras & 10538 & 8843 \\
\hline Linguística & 6604 & 2551 \\
\hline Museologia & 453 & 210 \\
\hline Teologia & 1310 & 913 \\
\hline
\end{tabular}

Fonte: Dados da Pesquisa (Plataforma Lattes, 2017)

Das áreas das humanidades elegeuse a Filosofia pelas seguintes razões: por sua condição de disciplina paradigmática no campo das humanidades; por sua histórica relação com os primórdios das Ciências; e, do ponto de vista metodológico, os dados da Plataforma Lattes apontam que a Filosofia apresenta a maior proporção de artigos entre as suas produções (gráfico 1), favorecendo a justaposição com a WoS. 
Figura 1: Pesquisadores identificados na Plataforma Lattes por grandes áreas

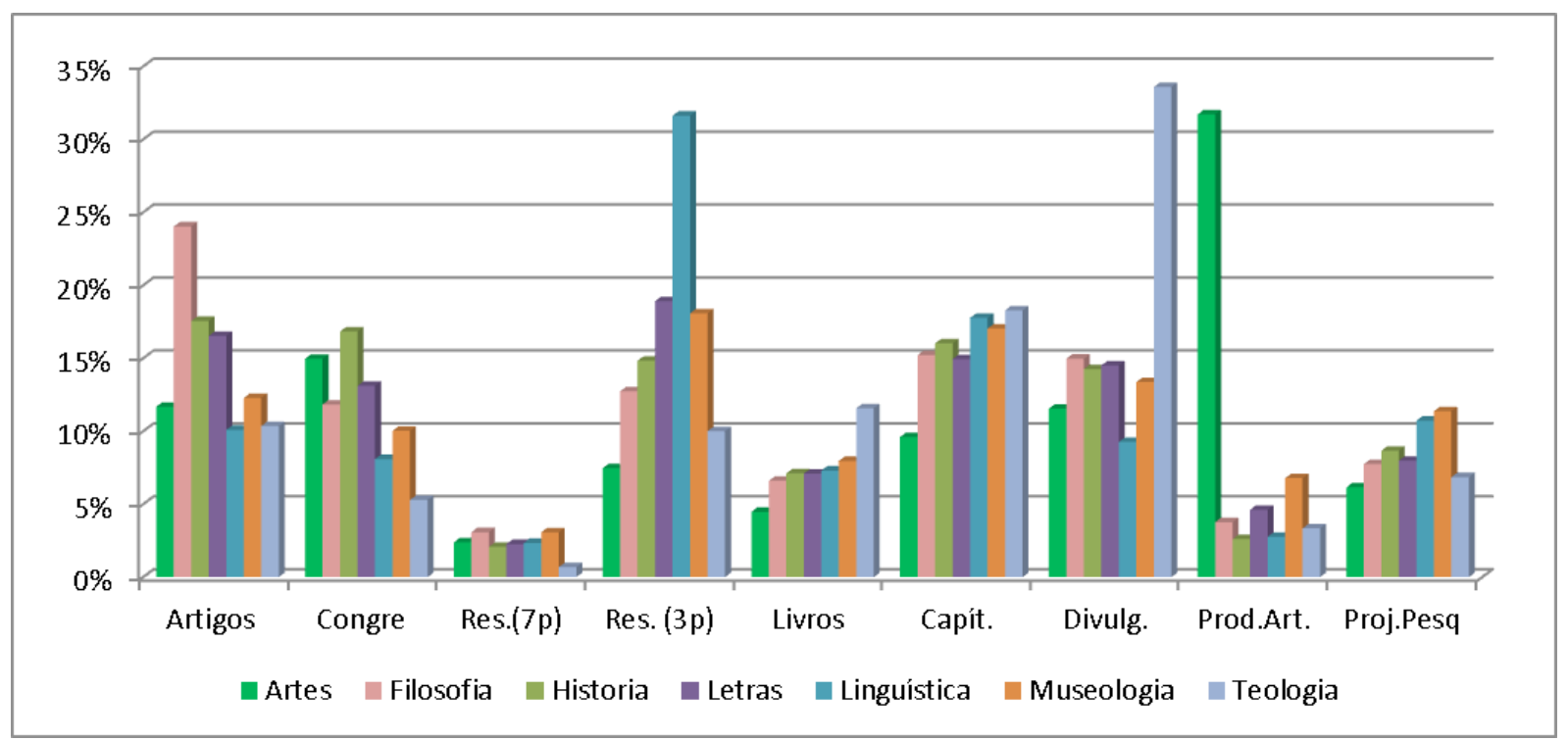

Fonte: Dados da Pesquisa (Plataforma Lattes, 2017)

Duas questões norteiam esta pesquisa: a justaposição entre os dados da Plataforma Lattes e WoS pode revelar diferentes comunidade hábitos de produção da área da Filosofia brasileira? Há semelhanças e diferenças entre as comunidades identificadas na justaposição?

Destarte, o objetivo deste trabalho é analisar a produção brasileira da área da Filosofia (20072016) a partir da justaposição de dados entre a Plataforma Lattes e a WoS para determinar se há distintas populações de pesquisadores quanto aos seus hábitos de publicação. Quanto aos objetivos específicos, buscar-se-á: conhecer a evolução temporal da produção científica em ambas as fontes; caracterizar a produção em ambas as fontes quanto ao idioma de publicação; estabelecer os periódicos onde difundem majoritariamente suas publicações (núcleo e dispersão de periódicos); identificar as áreas temáticas as quais atuam os pesquisadores; e, determinar como interagem os pesquisadores a partir da análise de coautoria e dos grupos de pesquisa e temáticas de seus interesses.

\section{REFERENCIAL TEÓRICO}

Algumas características diferenciam as humanidades das demais áreas, tais como: publicam-se muito mais monografias e capítulos de obras coletivas que outras áreas; quando optam por periódicos, preferem as nacionais; e, adotam com maior intensidade a língua vernácula (enquanto em outras áreas é crescente a convergência para a língua inglesa) (NEDERHOF, 2006; SANZ-CASADO, LASCURAIN-SÁNCHEZ; IRIBARREN-MAESTRO, 2007; HUANG; CHANG, 2008; ENGELS e outros, 2012, OSSENBLOK e outros, 2012; SIVERTSEN, 2016).

Como sinalado na Declaração de São Francisco (DORA, 2013) e no Manifesto de Leiden (HICKS et al, 2015), avaliar a produção científica das humanidades também não é uma tarefa simples. As instâncias políticas e a sociedade cada vez mais demandam uma adequada avaliação do impacto científico, social e político das pesquisas nas Ciências Sociais e Humanas (REALE et al., 2017).

As dificuldades agravam-se pelo fato de que publicações em língua inglesa são preteridas pelas grandes bases de dados internacionais utilizadas nas avaliações das produções científicas (NEDERHOF, 2006; ENGELSet al., 2012). Do ponto de vista bibliométrico, há dificuldades para avaliar a produtividade, visibilidade, impacto, colaboração entre estes investigadores. Ademais de ser dificultoso comparar dados entre países, exigindo-se mais fontes de dados e novos procedimentos. (ENGELS E OUTROS, 2012; VAN LEEUWEN, 2013; THELWALL E DELGADO, 2015; OCHSNER E OUTROS, 2016; OSCHBER E OUTROS, 2017; BONACCORSI, 2018). 
Comparados às demais áreas, os estudos bibliométricos nas Humanidades não são recentes, todavia são escassos. Em 1988, Nederhof, Zwaan, De Bruin, e Dekker avaliaram o uso de indicadores bibliométricos nos Países Baixos para disciplinas nas Ciências Humanas, Ciências Sociais e comportamentais. Naquele momento, tal como hoje, foram proeminentes questões referentes a língua, tipologias documentais e questionamentos sobre a cobertura da base ISI nas humanidades. Enquanto Finkenstaedt (1990) avaliou as dificuldades de aplicação da análise quantitativa as humanidades e a resistência geral a essa análise na Alemanha, além da prevalência de publicações sem coautoria.

Outros estudos como os Nederhof, Zwaan (1991), Nederhof, Raan (1992), Alcaín; San Millan Bujandas (1993), Hemlin, Gustafsson (1996) seguiram propósitos similares ao buscarem caracterizar e diferenciar a produção das humanidades. Há também textos que discutiram a dos periódicos em humanidades, são exemplos os de Kavunenko, Khorevin, Luzan (2006), Borrego, Urbano (2006). Enquanto Ochsner, Hug e Daniel (2015) traçam um perfil da produção das humanidades e apontam percursos direcionados a critérios e procedimentos para a avaliação, tendo alguns casos de países da Europa como exemplos.

Por sua parte, Franssen y Wouters (2017) analisam a representação das Humanidades ao longo da história da Bibliometria em dois períodos definidos. O primeiro (1965-1989) com estudos sobre o marco teórico, o uso do índice de Price e as análises de periódicos como fonte de dados. O segundo (desde meados dos anos 1980), mais relacionado com as políticas científicas e de avaliação com a Bibliometria como ferramenta de análise.

\section{MATERIAL E MÉTODOS}

\section{I Identificação dos pesquisadores e extração dos dados}

\section{a) Plataforma Lattes}

A Plataforma Lattes (http://lattes.cnpq. br) é uma base de dados brasileira de currículos de pesquisadores, criada e gerenciada pelo CNPq (Conselho Nacional de Desenvolvimento
Científico e Tecnológico). Os registros são todos inseridos pelos pesquisadores. Em novembro de 2016 havia 132.631 doutores cadastrados (http:/ / estatico.cnpq.br/painelLattes/mapa/).

Utilizando a ferramenta de busca da plataforma, primeiro identificaram-se os currículos dos pesquisadores brasileiros atuantes na área das Ciências Humanas utilizando os seguintes critérios: ser brasileiro (a) e estar atuando no Brasil; ter o título de doutor; estar vinculado a um grupo de pesquisa certificado pelo CNPq; ter atualizado o currículo nos últimos 12 meses; e ter indicado no campo Área de atuação que atua em uma das seguintes áreas: Filosofia, História, Teologia, Museologia, Artes, Letras, Linguística ${ }^{1}$.

A Tabela de área de conhecimento do $\mathrm{CNPq}$ está estruturada hierarquicamente no seguinte esquema: GRANDE ÁREA>ÁREA $>$ SUBÁREA>ESPECIALIDADE. É obrigatório indicar ao menos uma área de atuação e facultado indicar outras. É possível tanto indicar quaisquer áreas como incluir uma nova, mas a segunda condição não é estimulada pelo sistema.

Os dados dos currículos foram coletados e compilados durante os meses de outubro a novembro de 2017 utilizando-se a ferramenta Scriptlattes v.8.13 (http://scriptlattes. sourceforge.net/).

Em segundo momento foram extraídos os registros de artigos dos pesquisadores que atuam na área da Filosofia, totalizando 43.345 (sem limpeza). Esse número varia conforme o conjunto de dados necessários para determinada análise. Essa variância decorre da ausência de controle na entrada dos dados, que como se sabe, é de responsabilidade dos pesquisadores. Por isso há registros que não servem para um tipo de indicador, porém que são aptos para outro. Nos casos de haver tal diferença, uma menção será feita.

\section{b) Web of Science}

Em setembro de 2017 extraiu-se, a partir das bases da Coleção principal da WoS (SCIExpanded, SSCIy A\&HCI), 44.163 registros de artigos publicados de 2007 a 2016 com pelo

\footnotetext{
I Áreas contempladas pelas humanidades segundo a tabela de conhecimento do CNPq http://lattes.cnpq.br/documents/II87I/24930/ TabeladeAreasdoConhecimento.pdf/
} 
menos um autor brasileiro (filtro $\mathrm{CU}=$ Brazil) de qualquer área do conhecimento.

Para coincidir os artigos de Filosofia da Plataforma Lattes com aqueles indexados na WoS, adotaram-se técnicas de comparação entre ambas as bases para estabelecer um nível de justaposição. As técnicas consistiam na identificação de coincidências entre os títulos dos artigos e os respectivos números de ISSN dos periódicos nos quais foram publicados. Assim foram identificados 1.657 artigos na WoS, o equivalente a $2,61 \%$ de toda a produção brasileira indexada nesta base (figura 1).

Figura 2: Representação da justaposição entre os artigos extraídos da Plataforma Lattes com a WoS

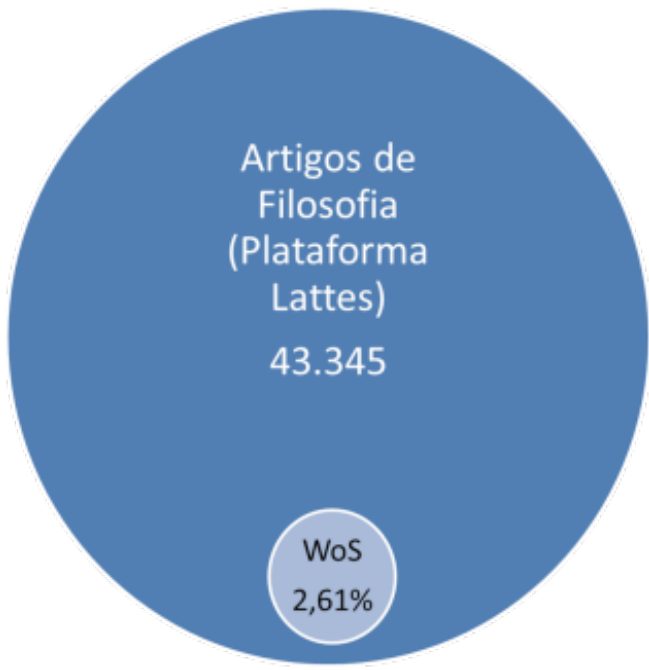

Fonte: Dados da Pesquisa (2017)

\subsection{Identificação das áreas singulares de atuação dos pesquisadores na plataforma lattes}

Consideram-se áreas singulares de atuação aquelas indicadas pelos autores como subordinadas a Filosofia, porém não previstas pela Plataforma Lattes (que adota a classificação de área do conhecimento do $\mathrm{CNPq}$ ). Os registros contendo dados de identificação de todos os pesquisadores do corpus deste estudo foram extraídos pelo ScriptLattes v.8.13 e importados para uma planilha do Microsoft Excel 2010.

\subsection{Identificação dos idiomas dos artigos publicados}

\section{a) Plataforma Lattes}

Para identificar a língua de publicação dos artigos utilizou-se o pacote Fran ${ }^{2}$ em linguagem de programação R. Para este fim foram adotados os títulos dos artigos registrados na Plataforma Lattes, considerando que o pesquisador, ao preencher o currículo, manteve o título do artigo original publicado.

Devido ao elevado número de registros $(41.145)^{3}$, adotou-se um processo de aferição do grau de assertividade utilizando a seguinte sistemática de amostragem: primeiro ordenaramse os títulos em ordem alfabética, depois se atribuiu o primeiro registro como ponto de início e intervalos específicos para verificar se estavam corretos (500 para a língua portuguesa, 50 para as línguas inglesa e espanhola, 25 para a língua francesa e 10 para outras línguas ou que não foi possível identificar devido a erros nos registros). A revisão foi continuamente sendo feita até alcançar, para cada língua, uma margem máxima de $10 \%$ de erro.

\section{b) WoS}

Análogo ao procedimento adotado para os dados da Plataforma Lattes, utilizou-se o pacote Fran (linguagem R), porém, a quantidade inferior de registros possibilitou que a revisão fosse feita em todos os registros.

\subsection{Identificação temática dos artigos}

Para identificar e relacionar os temas foram trilhados dois percursos: o primeiro baseou-se nas categorias temáticas definidas pela WoS; o segundo a partir da descoberta e relacionamento de tópicos temáticos segundo a técnica de modelos estatísticos "Topic Modeling".

\footnotetext{
2 https://github.com/MangoTheCat/franc

3 O valor corresponde aos registros passíveis de identificação do idioma, sendo excluídos aqueles com total ou parcial ausência de dados ou com caracteres incompatíveis com o pacote.
} 
O primeiro percurso foi passível somente para os registros da WoS por essa base prever o campo temático baseado em classificação própria. Como são muitas as categorias, optouse por reclassificar os artigos segundo a proposta de categorias para a WoS, de Glanzel \& Schubert (2003) (Quadro 1).

Quadro 1: Categorias Temáticas principais propostas por Glanzel \& Schubert

1. AGRICULTURE \& ENVIRONMENT
2. BIOLOGY (ORGANISMIC \&
SUPRAORGANISMIC LEVEL)
3. BIOSCIENCES (GENERAL, CELULAR \&
SUBCELLULAR BIOLOGY; GENETICS)
4. BIOMEDICAL RESEARCH
5. CLINICAL AND EXPERIMENTAL
MEDICINE I (GENERAL \& INTERNAL
MEDICINE)
6. CLINICAL AND EXPERIMENTAL
MEDICINE II (NON-INTERNAL MEDICINE
SPECIALTIES)
7. NEUROSCIENCE \& BEHAVIOR
8. CHEMISTRY
9. PHYSICS
10. GEOSCIENCES \& SPACE SCIENCES
11. ENGINEERING
12. MATHEMATICS
13. SOCIAL SCIENCES I (GENERAL,
REGIONAL \& COMMUNITY ISSUES)
14. SOCIAL SCIENCES II (ECONOMICAL \&
POLITICAL ISSUES)
15. ARTS \& HUMANITIES

Fonte: GLANZEL \& SCHUBERT (2003).

O segundo percurso surgiu como uma alternativa a limitação dos registros da Plataforma Lattes para identificar temas. Assim foram aplicadas técnicas de "topic modeling" para aferir os temas mais recorrentes e como estes se relacionam no conjunto analisado baseando-se nos títulos dos artigos.

A técnica "topic modeling" consiste em um modelo probabilístico aplicável a coleções de dados discretos como, por exemplo, os corpos textuais (BLEI, NG \& JORDAN, 2003). O método aplicado é o Latent Dirichlet Allocation (LDA), um método hierárquico bayesiano em que cada termo do conjunto de documentos é modelado segundo sua probabilidade de pertencer a cada um dos tópicos propostos.

Por outro lado, se utilizou o método proposto por Murzintcev (2015) para determinar o número ótimo de tópicos a incluir nas análises, cujo valor identificado foi cinco, comprovandose efetivamente que se trata dos tópicos mais representativos da área, tal e como se observa nos mapas gerados.

\subsection{Identificação do núcleo e dispersão dos periódicos}

Utilizou-se o modelo proposto por Bradford (1934) para identificar a concentração de trabalhos nos periódicos nucleares. Neste artigo se considerou que formam o núcleo aqueles periódicos que acumulam 33\% dos trabalhos objeto do estudo, tanto da Plataforma Lattes como da WoS.

\subsection{Grafo de coautoria}

\section{a) Plataforma Lattes}

Ao extrair dados da Plataforma Lattes com o Scriptlattes v.8.13 se gera um arquivo com a extensão .gdf, que serviu para elaborar grafos de coautoria com o software Gephi versão 0.9.2.

Em princípio foram identificados 6.060 nós (atores da rede) e 1.947 arestas, todavia, ao excluir os atores sem coautoria no conjunto, o número de nós foi reduzido para 1.756. Em seguida, fezse a distribuição utilizando a opção Force Atlas com força de repulsão 15.000. A partir da opção Estatísticas foram calculadas as medidas de centralidade de proximidade e centralidade de intermediação (que indicam a influência dos nós) que foram usadas como atributos para gerar o grafo. Por fim, para ajustes, fez-se nova distribuição Force Atlas com a opção Ajustar tamanho.

Para destacar os grupos mais sobressalentes, optou-se por aqueles de maior modularidade e com um mínimo de cinco publicações em coautoria, totalizando 39 pesquisadores distribuídos em quatro clusters. 


\section{b) WoS}

Primeiro coincidiu-se os títulos, ISSN e nomes dos periódicos dos 1.627 artigos justapostos na WoS e Plataforma Lattes. Em seguida importou-se os nomes dos autores da Plataforma Lattes, totalizando 5.232. Foram identificadas diferentes entradas para um mesmo autor além de erros de digitação, então para efetuar a limpeza dos dados e gerar uma matriz utilizou-se a ferramenta Vantage Point, resultando em 4.339 nomes de autores. Foi utilizado o Gephi 0.9.2 para a importação da matriz e criação do grafo. Para elaborar o grafo adotou-se como requisito um mínimo de cinco publicações em coautoria, totalizando 202 autores, o quíntuplo da Plataforma Lattes.

\section{RESULTADOS E DISCUSSÃO}

\section{I Evolução da produção}

O gráfico 2 representa a evolução da produção por tipologias (somente com os registros da Plataforma Lattes). Vê-se que a partir do ano de 2013 os trabalhos de eventos (completos, resumos e resumos expandidos) decaem, enquanto artigos, livros (e capítulos) tendem a crescer. $\mathrm{O}$ ano coincide com a mudança de um ciclo avaliativo dos programas de pós-graduações brasileiros, coordenado pela CAPES (instituição subordinada ao Ministério da Educação) que é baseado em critérios, dos quais a produção intelectual do corpo docente é sempre valorada. Os critérios são publicados por comissões específicas de cada área do conhecimento no "Documento de Área" e são aplicáveis para cada ciclo quadrienal de avaliação. O Documento de Área da Filosofia de $2013^{4}$ valoriza a produção qualificada de artigos, livros e capítulos de livros, tendo como parâmetro de qualidade o Qualis (sistema brasileiro de avaliação de periódicos e livros). Porém, faz breve alusão aos trabalhos completos de congresso e não menciona resumos.

4 http://www.capes.gov.br/images/stories/download/ avaliacaotrienal/Docs_de_area/Filosofia_Teologia_doc_area_e_ comiss\%C3\%A3o_2lout.pdf
Gráfico 2 - Evolução da produção bibliográfica em Filosofia (2007/2016)

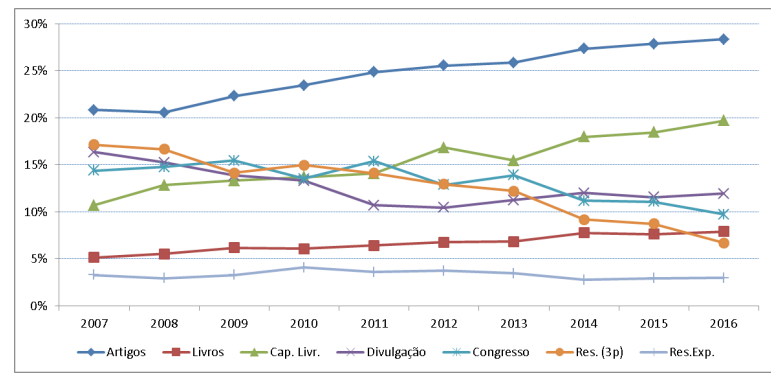

Fonte: Dados da Pesquisa (Plataforma Lattes, 2017)

Na WoS tem sido crescente a cobertura da produção brasileira (LETA, 2012 ; COLLAZO-REYES, 2013) e ainda que outros fatores possam justificar a redução em 2013 (Gráfico 3), há de se considerar que é o ano inicial do ciclo avaliativo da CAPES. Em contrapartida, a participação da Filosofia na WoS revela oscilações e declínio (Gráfico 4) nos últimos anos, reforçando a desproporcionalidade da cobertura desta base para as áreas das Humanidades.

Gráfico 3: Artigos brasileiros de todas as categorias (WoS)

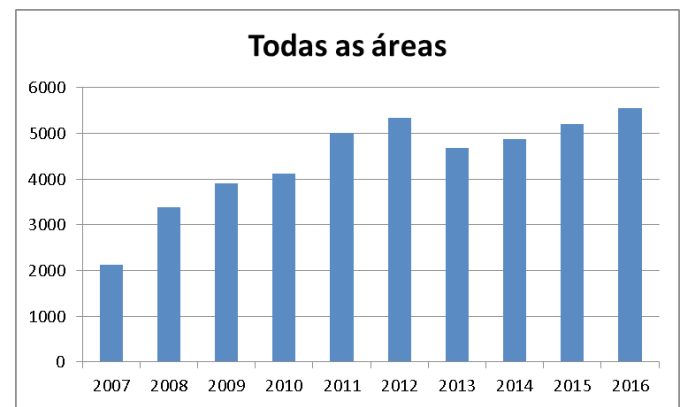

Fonte: Dados da Pesquisa (WoS, 2017)

Gráfico 4: Artigos brasileiros somente da categoria Filosofia (WoS)

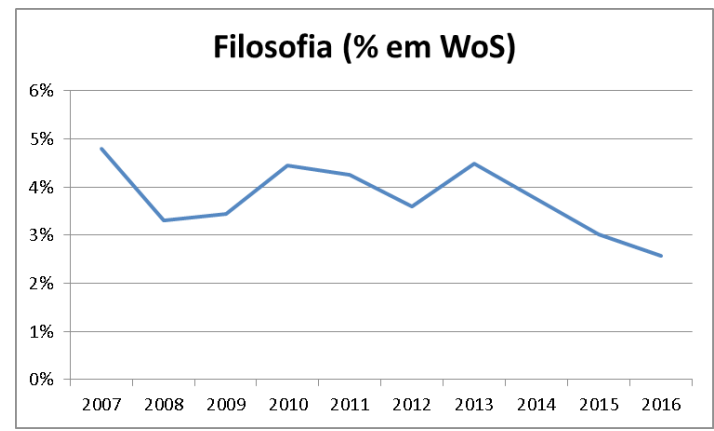

Fonte: Dados da Pesquisa (WoS, 2017) 
Os gráficos 5 e 6 baseiam-se nos registros de Filosofia da WoS (justapostos com a Plataforma Lattes) e todos de Filosofia da Plataforma Lattes. Enquanto na primeira metade da década há um crescimento na WoS, um revés é percebido na segunda. Na WoS a média foi de 162,7 artigos por ano, sendo 148,8 no primeiro quinquênio e 176,6 no segundo, cujo coeficiente de $\mathrm{R}^{2}=0,2111$ da linha de tendência revela que a amostra não se ajusta adequadamente. A Plataforma Lattes registra uma média de 4.334,5 para a década, porém se dividido em dois quinquênios tem-se 3.982,4 artigos de 2007 a 2011, e 4.686,6 artigos de 2012 a 2016. Para a Plataforma Lattes a linha de tendência obteve um coeficiente $\mathrm{R}^{2}=0,7058$, demonstrando uma amostra satisfatória.

Gráfico 5: Artigos justapostos de Filosofia (WoS)

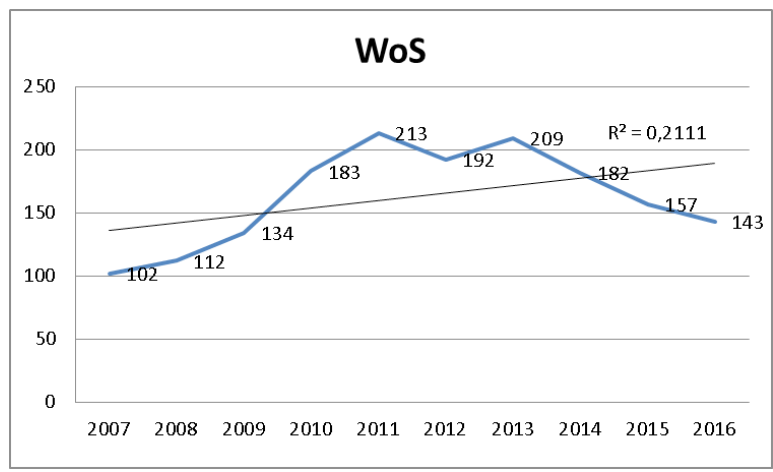

Fonte: Dados da Pesquisa (WoS e Plataforma Lattes, 2017)

Gráfico 6: Artigos de Filosofia (Lattes)

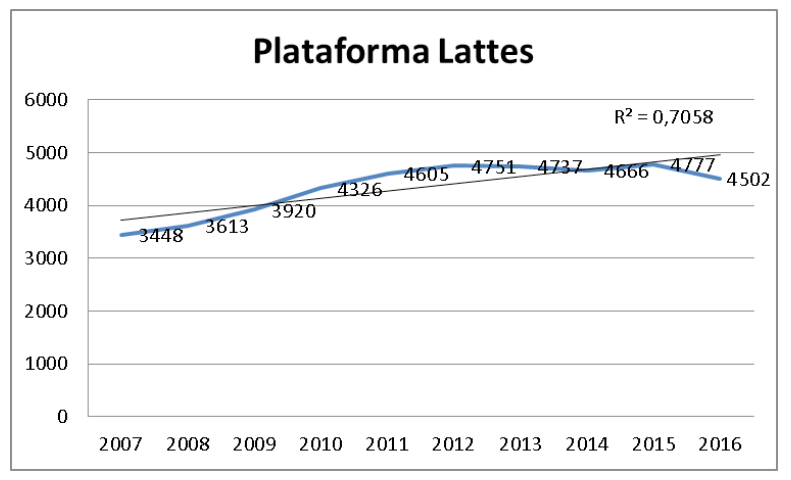

Fonte: Dados da Pesquisa (Plataforma Lattes, 2017)

\section{2 Áreas singulares de atuação}

Os perfis mais singulares de pesquisadores são aqueles que alcançaram a maior incidência de artigos indexados na WoS. Esses se diferenciam dos demais pelas relações de coautoria, pela escolha dos periódicos em que publicam artigos e pelas temáticas de suas pesquisas. Igualmente peculiar é a forma que alguns indicam as áreas que atuam na Filosofia, incluindo e estabelecendo relações de subordinação entre campos do conhecimento não previstos na tabela de área de conhecimento do CNPq.

Há, por exemplo, relações de subordinação de certas áreas do conhecimento à Filosofia indicando uma auto-reflexão do próprio campo ou domínio do conhecimento, como: Filosofia da biologia, Filosofia da mente, Filosofia da natureza e Filosofia da psicanálise. Também se identificaram subáreas da Filosofia relacionadas a estudos epistemológicos, por exemplo, Epistemologia da Psicologia, da Epistemologia da psicanálise e Epistemologia das Ciências da Saúde.

Contudo, o destaque recai nos estudos relativos a ética/bioética atrelados as Ciências da vida, como: Bioética; Bioética e Biosseguranca; Ética Aplicada a Animais; Ética e Tecnologia; Ética em Psicologia; Ética e Biossegurança; Ética e Medicina; Ética Animal, Ética Ambiental.

A bioética enquanto campo transdisciplinar é transversal e busca responder aos conflitos e dilemas que versam sobre a vida e a saúde (PORTO, 2017). No Brasil a história da bioética inicia em meados dos anos 1990 com a Resolução 196/96 do Ministério da Saúde, que entre outras ações estabeleceu a Sociedade Brasileira de Bioética. Outro importante marco foi a institucionalização de disciplinas relacionadas a bioética em cursos de graduação e pós-graduação, contribuindo para a consolidação dos temas na academia (DINIZ, GUILHEM \& GARRAFA, 1999).

Em 2003 o Ministério da Saúde, em conjunto com o Ministério de Ciência e Tecnologia, estabeleceram uma agenda de prioridades para investimentos na área da Saúde para o horizonte temporal de 2004 a 2012. Neste momento a denominada área de Estudos éticos e Bioéticos captou um montante de recursos (US\$1.421 milhões em 98 projetos) que representou um avanço significativo para a área (SANTOS et al., 2011). 
A fase de maior avanço e consolidação dos estudos bioéticos no Brasil é concomitante com o período contemplado de análise da produção científica. A convergência de esforços somados ao processo de institucionalização de um domínio do saber se materializa de forma esparsa no movimento de um grupo de pesquisadores, que neste estudo é percebida como uma subcomunidade de pesquisadores das áreas da vida que atuam numa tênue linha fronteiriça com a área da Filosofia.

\subsection{Idiomas das publicações}

A identificação automática da língua de publicação alcançou resultados satisfatórios, tanto para os registros da Plataforma Lattes como para a WoS, ainda que para a primeira tenha sido necessário um esforço maior para revisar e corrigir as inconsistências. Nas tabelas 3 e 4 constam as respectivas línguas de publicação, antes e após revisões.
Tabela 3: Línguas Plataforma Lattes

\begin{tabular}{|l|c|c|}
\hline Língua & Antes da revisão & Pós-revisão \\
\hline Portuguesa & 35085 & 36720 \\
\hline Inglesa & 2596 & 2524 \\
\hline Espanhola & 2695 & 1259 \\
\hline Francesa & 729 & 506 \\
\hline Outras & 40 & 136 \\
\hline
\end{tabular}

Fonte: Dados da pesquisa (Plataforma Lattes, 2017)

Tabela 4: Línguas WoS

\begin{tabular}{|l|c|c|}
\hline Língua & Antes da revisão & Pós-revisão \\
\hline Portuguesa & 407 & 370 \\
\hline Inglesa & 1218 & 1232 \\
\hline Espanhola & 0 & 16 \\
\hline Francesa & 0 & 5 \\
\hline Outras & 2 & 5 \\
\hline
\end{tabular}

Fonte: Dados da pesquisa (WoS, 2017)

Comparando os resultados entre a Plataforma Lattes e a base WoS tem-se resultados antagônicos quanto as línguas de publicações (gráfico 7).

Gráfico 7: Idiomas das publicações

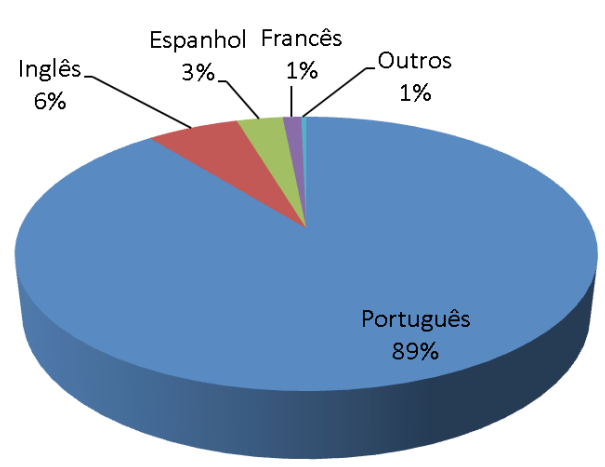

Plataforma Lattes

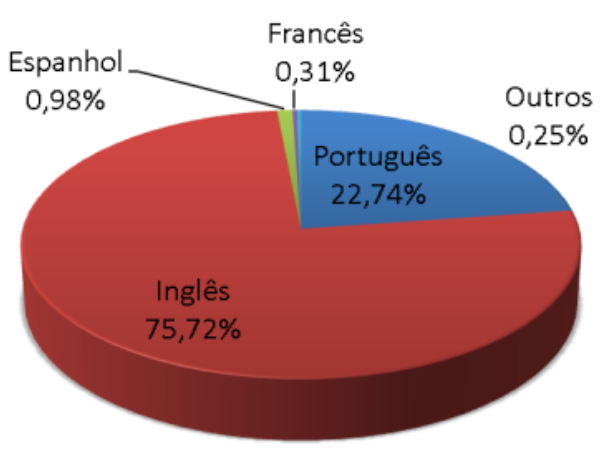

WoS

Fonte: Dados da Pesquisa (Plataforma Lattes e WoS)

$\mathrm{Na}$ Plataforma Lattes predominam os artigos em língua portuguesa (89\%), apontando a ampla predominância para a língua nativa, resultado esse esperado para a área das Humanidades. Em contrapartida, predominam nos artigos da WoS a língua inglesa $(75,72 \%)$, devido a alta incidência de artigos da área da saúde de autoria dos pesquisadores transeuntes, identificados na justaposição de artigos. 


\subsection{Núcleo e dispersão dos periódicos}

Os 43.273 registros de artigos identificados na Plataforma Lattes foram publicados em 9.780 periódicos diferentes. Considerando somente os periódicos que acumulam um terço dos artigos $(\mathrm{n}=14.393)$ (tabela 5), os denominados periódicos nucleares, somam 238 (2,43\% dos títulos), o que supõe uma produtividade média do núcleo de 60,43 artigos.

O periódico do núcleo com o maior número de artigos publicados, 218, é o Trans/forma/ção (UNESP). O segundo, ÉTICA (UFRJ), totaliza 199. Do núcleo, somente quatro periódicos não possuem linhas editoriais estritamente alinhados aos debates filosóficos, porém, o de número 15,

"Para entender a história", informa que se dedica a temas ligados a História, Filosofia e Educação.

Do núcleo, cinco periódicos são estrangeiros, dos quais quatro de língua espanhola e um de língua inglesa. Há mais outros quatro periódicos de língua inglesa, todos brasileiros.

Tabela 5: Núcleo e dispersão de periódicos Plataforma Lattes

\begin{tabular}{|c|c|c|}
\hline & $\begin{array}{c}\text { Periódicos } \\
\text { acumulados }\end{array}$ & $\begin{array}{c}\text { Artigos } \\
\text { acumulados }\end{array}$ \\
\hline Núcleo & 238 & 14393 \\
\hline Zona 1 & 1299 & 14855 \\
\hline Zona 2 & 8243 & 14025 \\
\hline & 9780 & 43273 \\
\hline
\end{tabular}

Fonte: Dados da Pesquisa (Plataforma Lattes, 2017)

Na WoS se observou uma maior concentração nos artigos recuperados. Os 1.627 artigos estão em 723 periódicos e o núcleo é composto por 35 periódicos (33,62\%) (tabela 6), sendo a produtividade de 15,73. O periódico mais produtivo do núcleo é Ciencia \& Saúde Coletiva com 82 artigos, seguido de Cadernos de Saúde Pública com 39. Quanto aos escopos, prevalecem os dedicados às Ciências da Vida, Matemática e Física. No entanto, entre os dez periódicos com maior incidência, dois estão relacionados ao ensino: Ensenanza de Las Ciencias e Science \& Education. No núcleo da WoS, a conexão interdisciplinar com a Filosofia é mais explícita nas questões éticas tratadas em três periódicos: Developing World Bioethics, Acta Bioethica, e Journal of Medical Ethics.
Tabela 6: Núcleo e dispersão de periódicos WoS

\begin{tabular}{|c|c|c|}
\hline & $\begin{array}{c}\text { Periódicos } \\
\text { acumulados }\end{array}$ & $\begin{array}{c}\text { Artigos } \\
\text { acumulados }\end{array}$ \\
\hline Núcleo & 35 & 547 \\
\hline Zona 1 & 213 & 605 \\
\hline Zona 2 & 475 & 475 \\
\hline & 723 & 1627 \\
\hline
\end{tabular}

Fonte: Dados da pesquisa (WoS, 2017)

Nos gráficos 8 e 9 se mostram as dispersões das publicações em ambas fontes em escalas semilogarítmicas.

\section{Gráfico 8: Dispersão (Plataforma Lattes)}

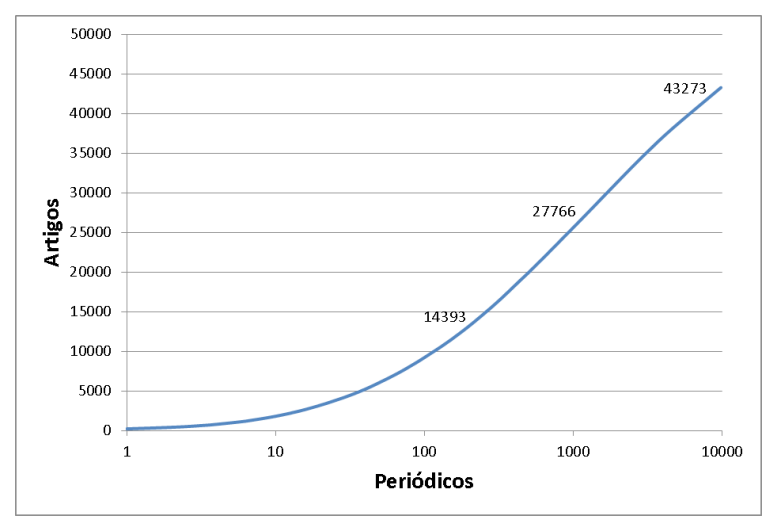

Fonte: Dados da pesquisa (Plataforma Lattes, 2017)

Gráfico 9: Dispersão (WoS)

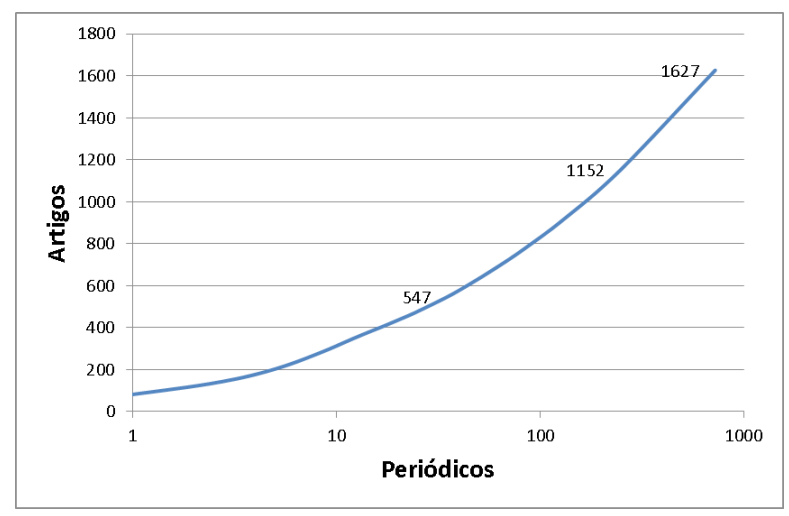

Fonte: Dados da pesquisa (WoS, 2017)

Dos núcleos de ambas as bases coincidem 11 periódicos conforme a tabela 6 . 
Tabela 6: Justaposição nos núcleos de periódicos da WoS e Plataforma Lattes

\begin{tabular}{|l|c|c|}
\hline Periódico & $\begin{array}{c}\text { Qtde. Artigos em } \\
\text { WoS }\end{array}$ & $\begin{array}{c}\text { Qtde. Artigos em } \\
\text { Plataforma Lattes }\end{array}$ \\
\hline Ciencia \& Saúde Coletiva & 82 & 87 \\
\hline Cadernos de Saúde Publica & 39 & 63 \\
\hline Revista da Escola de Enfermagem da USP & 29 & 45 \\
\hline Enseñanza de Las Ciencias & 27 & 38 \\
\hline Genetics and Molecular Research & 26 & 35 \\
\hline Science \& Education & 25 & 29 \\
\hline Movimento & 22 & 44 \\
\hline Revista Latino-Americana de Enfermagem & 17 & 30 \\
\hline Saúde e Sociedade & 17 & 32 \\
\hline Revista Latinoamericana de Psicopatologia Fundamental & 11 & 32 \\
\hline $\begin{array}{l}\text { Bolema-Mathematics Education Bulletin-Boletim de } \\
\text { Educação Matemática }\end{array}$ & 7 & 33 \\
\hline
\end{tabular}

Fonte: Dados da Pesquisa (Plataforma Lattes e WoS, 2017)

\subsection{A classificação temática dos artigos}

Devido a ausência de categorização dos registros da Plataforma Lattes, a primeira parte da análise temática dos artigos contemplou exclusivamente os registros da WoS. Considerando toda a produção recategorizada dos artigos conforme a proposta de Glanzel \&
Schubert (2011), sobressaem-se as investigações das Ciências da vida e comportamentais (Gráfico 10). Em princípio não se percebe afinidades entre objetos, métodos cognitivos e recursos instrumentais com a área da Filosofia, no entanto, como elemento de inter-relação disciplinar, destacam-se as questões sobre a ética, bioética, biossegurança, entre outras.

Gráfico 10: Artigos da WoS segundo as categorias de Glanzel \& Schubert

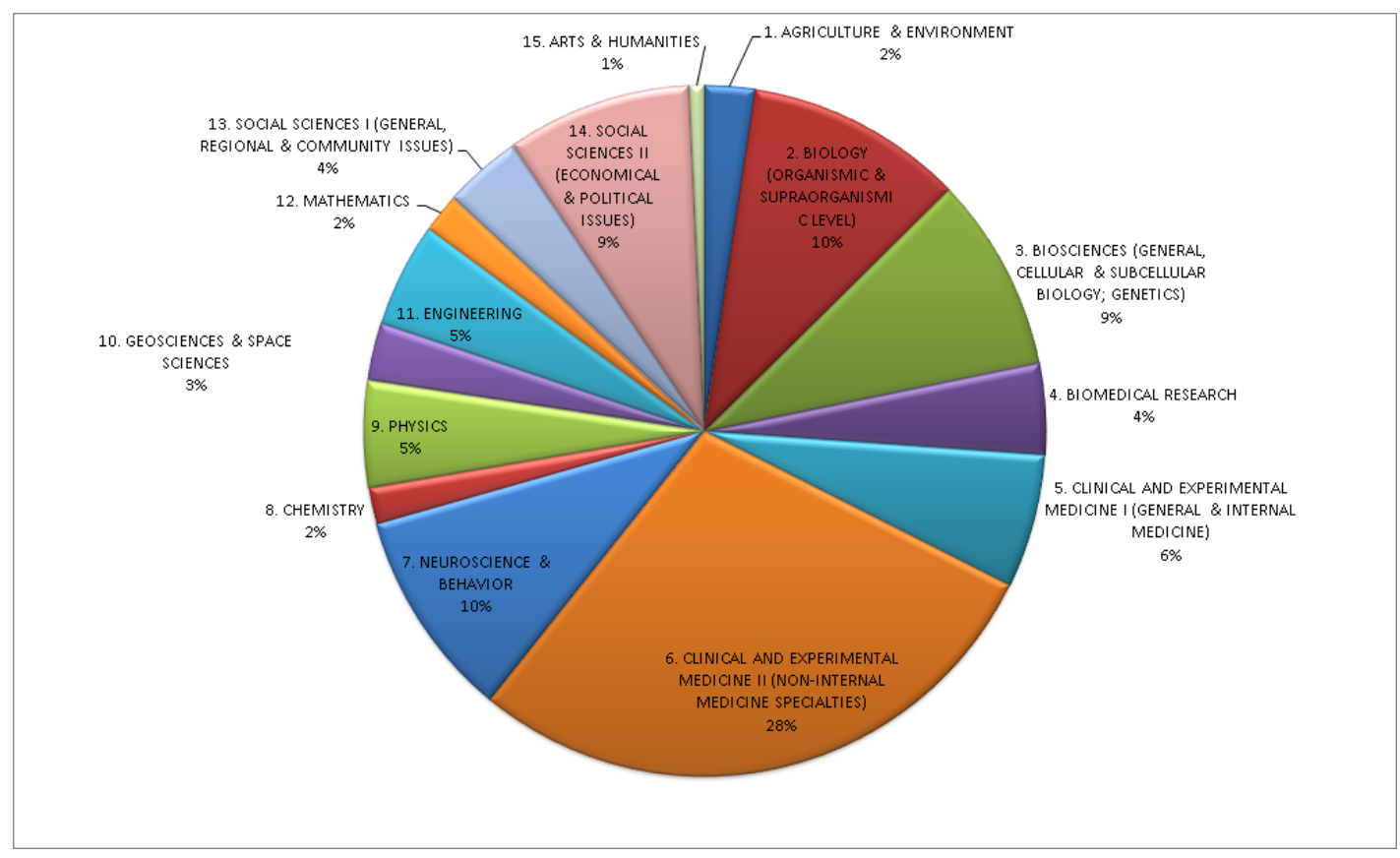

Fonte: Dados da Pesquisa (WoS, 2017)

Inf. \& Soc.:Est., João Pessoa, v.28, n.3, p. 245-262, set./dez. 2018 
Ao dividir-se em dois quinquênios prevalece certo equilíbrio quantitativo para quase todas as áreas. As exceções foram o aumento para as categorias 13 e 14 (Social Sciences I e II) de respectivamente $175 \%$ e $75 \%$ e a redução de $50 \%$ da categoria 15 (Arts \& Humanities). Esses são indicativos relevantes, pois são áreas com maior aderência disciplinar, vínculos de autoria e produção intelectual com a Filosofia.

A maior presença das Ciências Sociais brasileira na WoS nos cinco últimos anos foi favorecido pelo acréscimo de publicações na expansão da cobertura da base. Uma das ações que contribuiu para o aumento de periódicos brasileiros indexados na WoS foi a incorporação do SciELO Citation Index (SciELO CI) na plataforma Web of Science (WoS) iniciada em 2014 (PACKER, 2014). O Scielo CI é uma base de periódicos brasileiros de boa qualidade.

$\mathrm{Na}$ segunda parte da análise temática, baseada na relação de tópicos, os mapas foram elaborados conforme o destaque dos termos presentes nos títulos dos artigos, o primeiro (figura 2) baseia-se em dados da Plataforma Lattes.

Figura 2: Mapa de tópicos da Plataforma Lattes

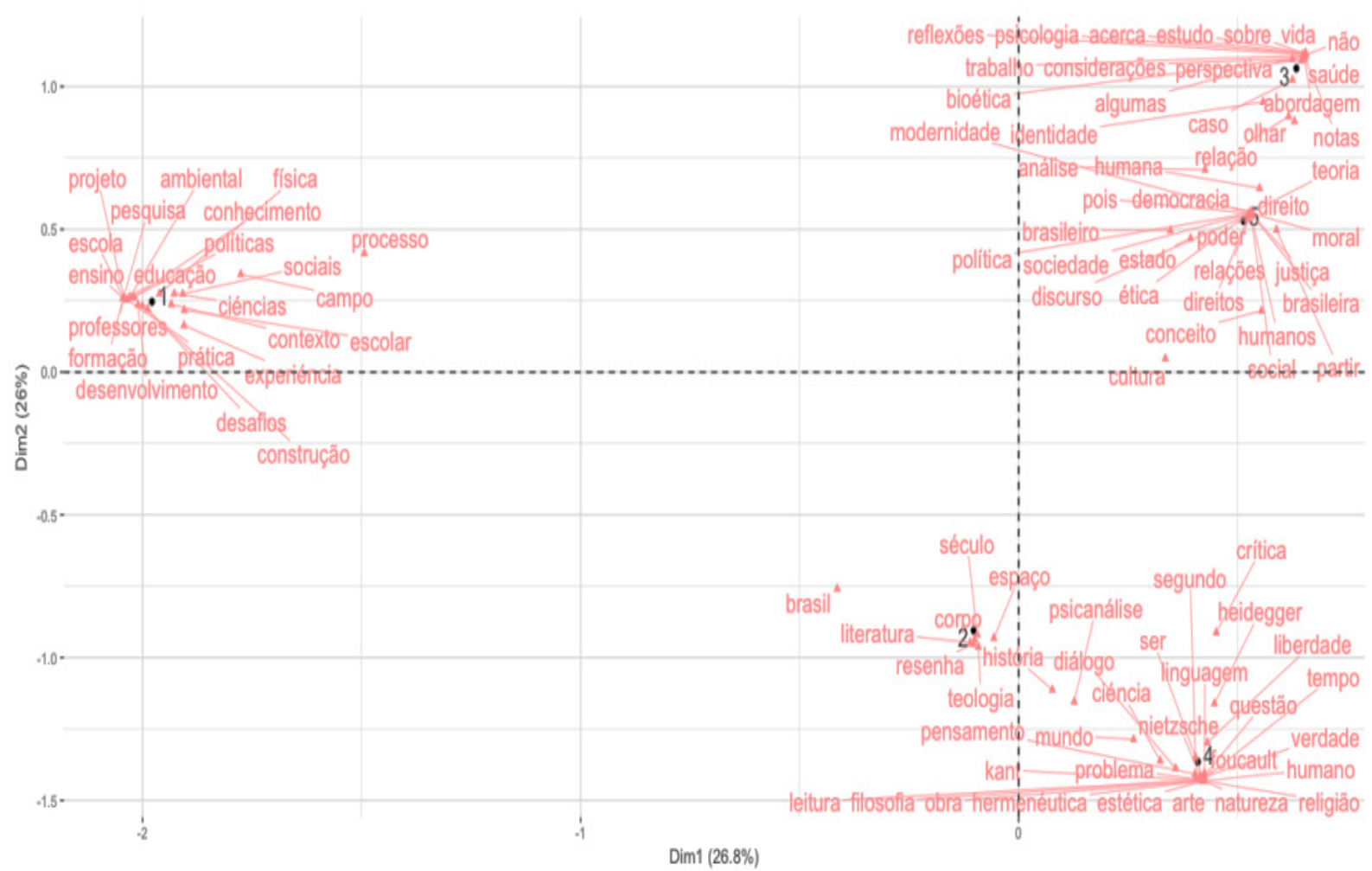

Fonte: Dados da Pesquisa (Plataforma Lattes, 2017)

Há três agrupamentos que se distinguem por respectivas aproximações semânticas. Esses agrupamentos possibilitam atribuir relações e inferências que sinalizam vertentes de investigações na comunidade analisada, indicando preferências por determinados objetos, métodos, ideologias. É plausível afirmar que no grupo 1 sobressaem-se aspectos pedagógicos como o ensino, educação, escola, professores, formação, estudo; no grupo 5 se destacam as dinâmicas institucionais como a democracia, direito, política, sociedade, justiça e ética; no grupo 3 se observam termos relacionados a vida, saúde, psicologia e bioética. A adjacência entre os grupos 3 e 5 decorre, conforme visto em outras análises deste estudo, da transdisciplinaridade 
entre os estudos éticos e das Ciência da vida. No grupo 4 se destacam os domínios de estudos críticos e da linguagem, sobressaltando autores como Nietzsche, Heidegger e Kant; onde se percebe uma interface com o grupo 2 nos tópicos de literatura, leitura e pensamento.

O mapa de tópicos da WoS (figura 3), se comparado ao mapa da Plataforma Lattes, diferencia-se do ponto de vista sintático pela predominância da língua inglesa e do ponto de vista semântico por prevalecer a terminologia das Ciências da vida.
Os grupos sinalizam uma comunidade mais homogênea quanto aos objetos de investigação se comparada ao mapa da Plataforma Lattes onde os grupos estão dispostos de forma mais polarizada e sem interseções claras. Os grupos estão identificados por números que variam de $\mathbf{1}$ a 5 , sendo o grupo 2 um núcleo equidistante dos demais. Os tópicos do grupo 2 desempenham a função de elo com um conjunto que majoritariamente trata de questões relativas a saúde e estudos clínicos numa perspectiva brasileira, justificando a centralidade de termos como heath, disease, clinical, brazilian.

Figura 3: Mapa de tópicos da WoS

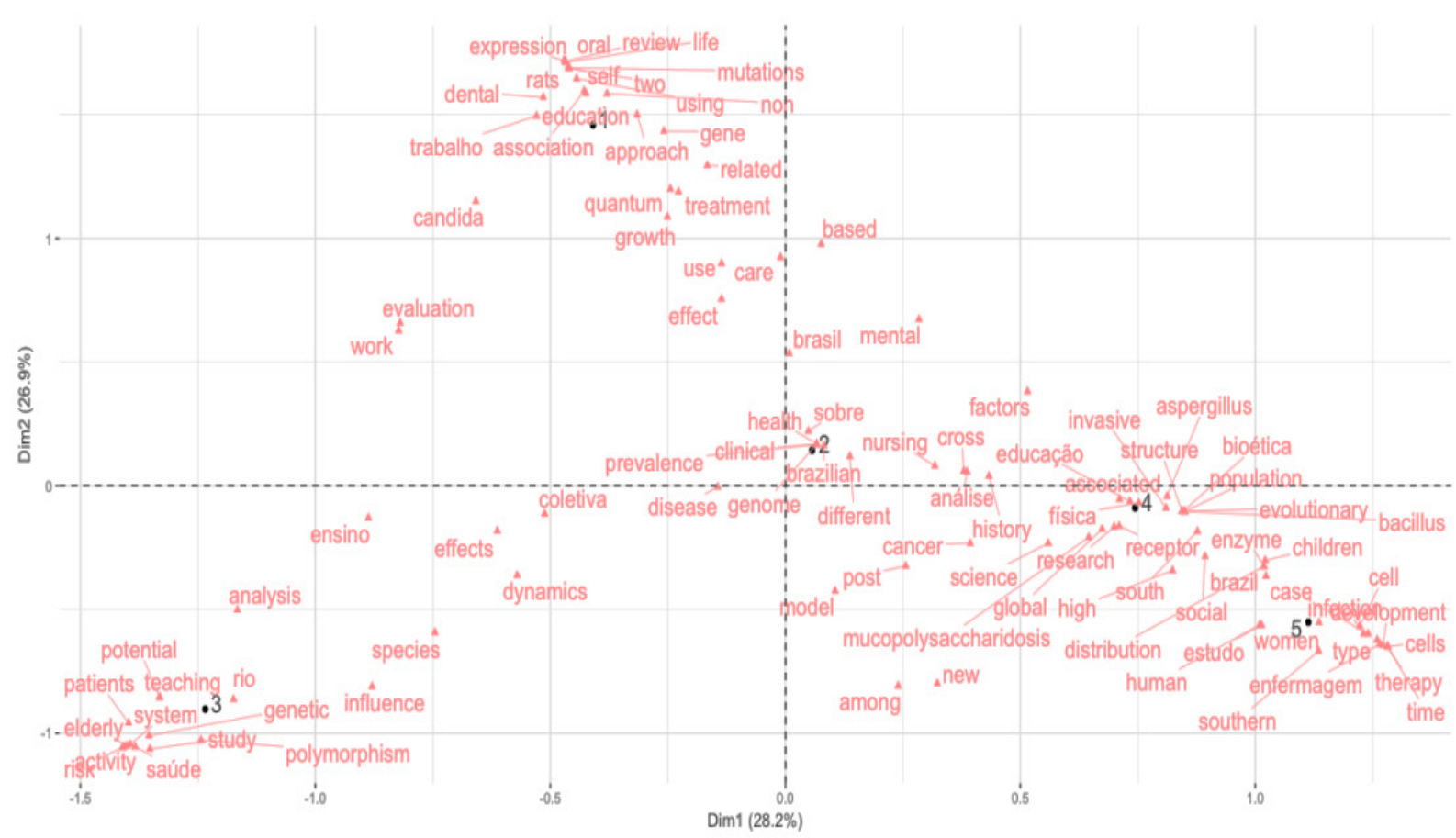

Fonte: Dados da Pesquisa (WoS, 2017)

\subsection{Grafo de coautoria}

As relações de coautoria da Plataforma Lattes coadunam com as análises de uma comunidade de pesquisadores das Ciências Humanas e Sociais, das quais se prevê interações interdisciplinares, sejam decorrentes dos domínios do saber de cada pesquisador ou da afluência de saberes entre grupos de pesquisa atuantes em temas afins. É factível afirmar que são estudos sobre contextos que tratam de questões: epistemológicas, pedagógicas, teológicas, literárias, linguísticas e sociais. $\mathrm{Na}$ figura 4 é possível distinguir os grupos por cores e correspondentes temáticas prevalecentes.

Percebeu-se que há compatibilidade entre a rede de coautoria da Plataforma com o mapa de tópicos desta mesma base. Para indicar as respectivas relações entre grupos de autores e de termos, foram inseridos na legenda de cores os números correspondentes a cada agrupamento de tópicos. Presume-se que esta convergência corrobore para o grau de confiabilidade das estratégias metodológicas adotadas para representar a comunidade deste estudo. 
Figura 4: Rede de coautoria Plataforma Lattes

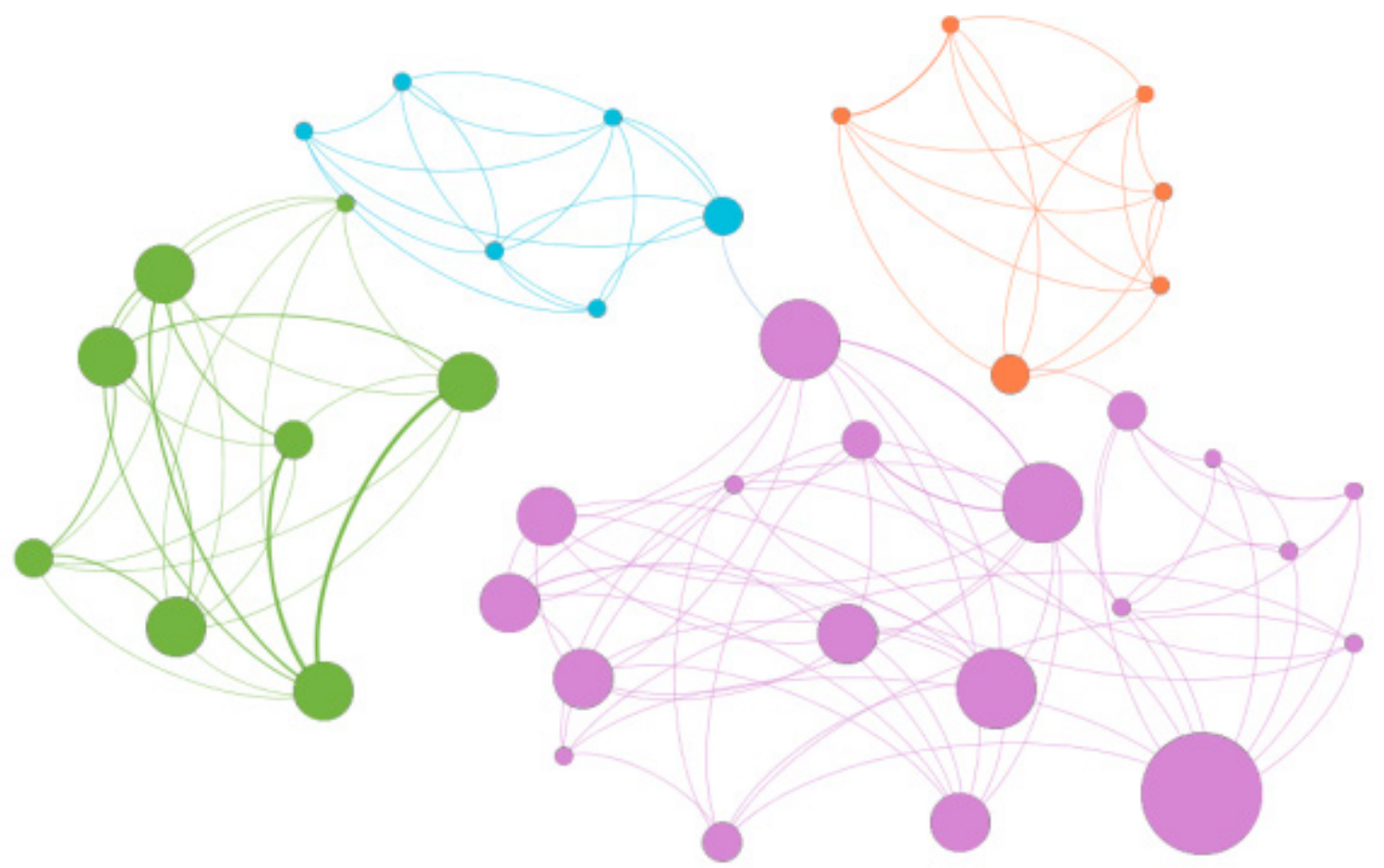

\begin{tabular}{|c|l|c|l|}
\hline 1 & $\begin{array}{l}\text { Educação, currículo e filo- } \\
\text { sofia do conhecimento. }\end{array}$ & 2 e 4 & $\begin{array}{l}\text { Religião, Literatura, Lín- } \\
\text { gua, Análise do discurso, } \\
\text { teoria da linguagem, Juris- } \\
\text { dição. }\end{array}$ \\
\hline 2 e 4 & $\begin{array}{l}\text { Teologia, arte, semiótica, } \\
\text { epistemologia, Direitos } \\
\text { humanos, movimentos so- } \\
\text { ciais, educação, Meio am- } \\
\text { biente e Política. }\end{array}$ & $\begin{array}{l}\text { Filosofia, Movimentos } \\
\text { sociais, Educação física, } \\
\text { Linguagem, Semiótica, co- } \\
\text { nhecimento, economia, lite- } \\
\text { ratura, Mulheres. }\end{array}$ \\
\hline
\end{tabular}

Fonte: Dados da pesquisa (Plataforma Lattes, 2017)

A rede de coautoria da WoS (figura 14) está moldada por pesquisadores mais vinculados as Ciências da vida, que diferenciam-se por publicarem com um maior número de coautores, um contraponto com as Ciências Humanas. Isso justifica a totalidade de autores da rede ser o quíntuplo daquela obtida na Plataforma Lattes.

Também é mais coesa ao ser comparada com a da Plataforma Lattes quanto aos objetos de estudo. É peculiar às Ciências Humanas e
SOCIAIS um nível maior de subjetividade em suas abordagens investigativas, contrapondose ao modelo mais positivista das Ciências da Vida. Essa diferença materializa-se nas especificidades dos domínios de conhecimento e nas terminologias de áreas, era previsto que essa distinção de áreas se explicitaria em relações de coautoria. Similar a figura 5, na legenda foram inseridos os números relativos aos grupos identificados no mapa de tópicos da WoS. 
Figura 5: Rede de coautoria WoS

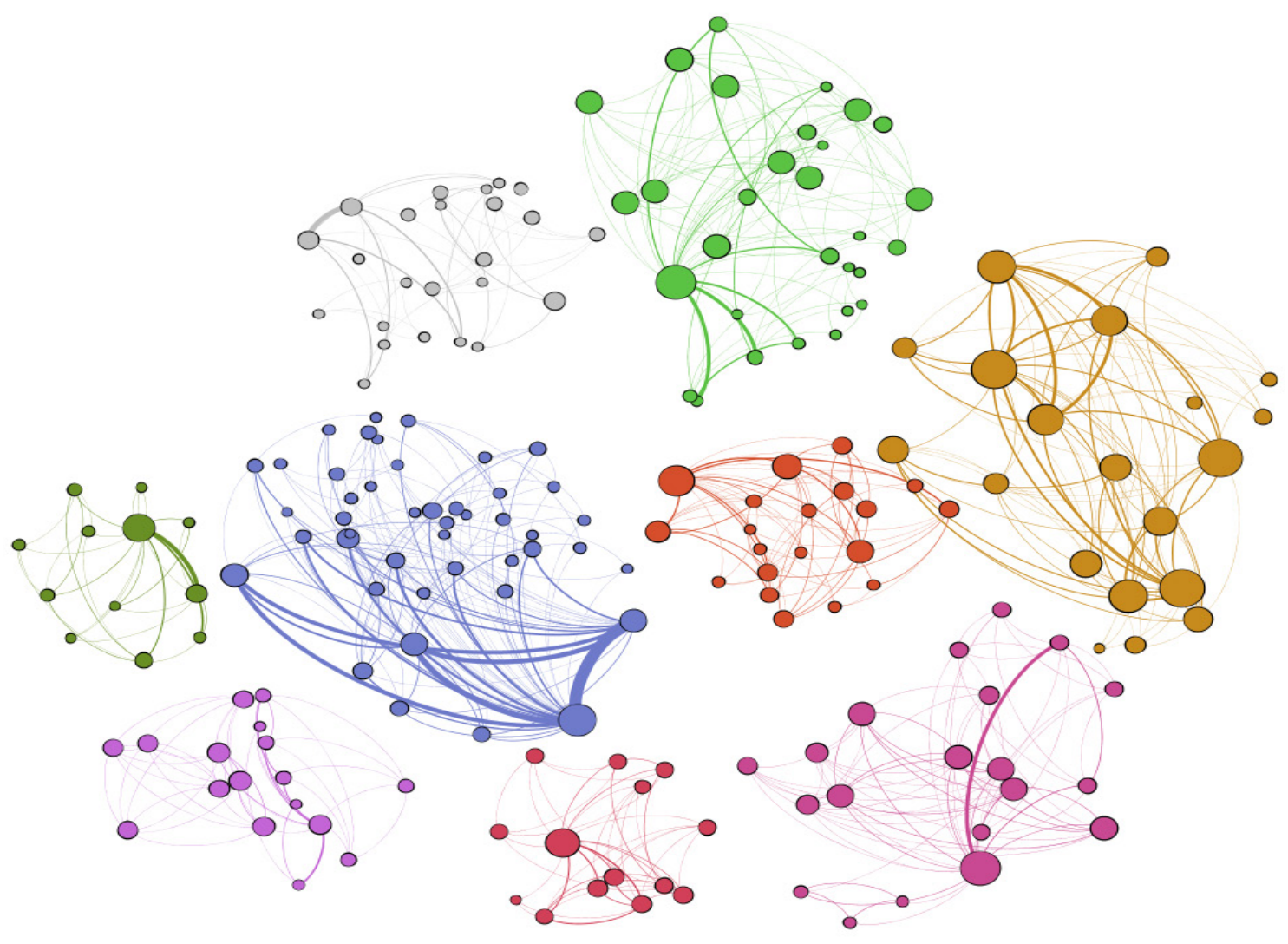

\begin{tabular}{|c|l|c|l|}
\hline 4 & $\begin{array}{l}\text { Fungus, allergy } \\
\text { aspergillosis, infection }\end{array}$ & 5 & $\begin{array}{l}\text { Hepatic, obesity, gene, } \\
\text { cell }\end{array}$ \\
\hline 3 & $\begin{array}{l}\text { Enzyme, Ensino, Crohn's } \\
\text { disease }\end{array}$ & 2 & $\begin{array}{l}\text { Mental, task, brazilian, } \\
\text { neurological }\end{array}$ \\
\hline 1 & Oral, cancer, dental & 3 & $\begin{array}{l}\text { HPV, polymorphism, } \\
\text { bacterial }\end{array}$ \\
\hline 4 & $\begin{array}{l}\text { Mucopolysaccharidosis, } \\
\text { therapy }\end{array}$ & 1 & $\begin{array}{l}\text { A n t i f u n g a l s, } \\
\text { Candidiasis }\end{array}$ \\
\hline 3 & Sleep, brazilian, study & & \\
\hline
\end{tabular}

Fonte: Dados da Pesquisa (WoS, 2017) 


\section{CONCLUSÕES}

Conciliar diferentes fontes de dados revelou um padrão subjacente de comportamento de publicações por parte de uma comunidade que, ao mesmo tempo em que se dedica aos domínios das Ciências da vida, declara atuar em ramos de conhecimento da Filosofia. Assim, conclui-se que a justaposição de dados entre as duas fontes fez emergir uma subcomunidade atípica, que pelas estratégias usuais de busca seria improvável reconhecê-la.

A respeito da evolução da produção, ambas as bases apresentaram uma média maior na segunda metade da década analisada, no entanto, enquanto a linha de tendência se ajustou bem aos dados da Plataforma Lattes, por outro foi pouco adequada aos valores da WoS. O quantitativo da WoS foram influenciados pela incidência de valores acima da média entre os anos de 2010 a 2015, período concomitante com um crescimento global da produção científica brasileira e um avanço dos estudos relativos a bioética.

O idioma português prevalece nos artigos da Plataforma Lattes com $89 \%$, enquanto para a língua inglesa são 6\%, isso corresponde a 2552 artigos. Considerando que para os dados da WoS houve 1232 artigos em inglês, resulta que dos 41.145 artigos que tiveram o idioma analisados da Plataforma Lattes somente 1320, ou 3,20\%, não estão indexados na WoS.

Os núcleos de periódicos têm perfis bastante distintos, enquanto que para os dados da Plataforma Lattes seja evidente a aderência dos títulos dos periódicos a área da Filosofia, para os dados da WoS a ênfase é na área da saúde. Ao relacionar os dois núcleos de periódicos em busca de títulos que coincidam se percebe que a lista resultante expressa somente o conjunto de pesquisadores advindos da justaposição entre as bases.

Na análise dos temas, no primeiro percurso baseado nas categorias da WoS, seguem em consonância com os demais resultados quando $67 \%$ do artigos foram categorizados em Ciências da vida, consolidando tal orientação. Por outro lado, os mapas de tópicos proporcionaram representações bastante interessantes sobre os dados da Plafatorma Lattes e WoS a partir dos títulos dos artigos. Igualmente significativo foi perceber que esses mapas harmonizam-se com a rede de coautores. A respeito das redes de coautoria, os números de autores para cada rede formada indicam diferentes hábitos de produção conjunta. Enquanto a rede de coautores elaborada com dados da Plataforma Lattes foi composta por 39 pesquisadores, a rede baseada em dados da WoS, seguindo o mesmo requisito mínimo de 5 produções em coautoria, totalizou 202 autores.

Sobre as estratégias metodológicas empregadas, considera-se que os resultados responderam satisfatoriamente as questões suscitadas na pesquisa, ainda que as diversas etapas sucedidas tenham exigido um laborioso esforço para conciliar e ajustar duas fontes distintas de dados. Para os próximos estudos propõem-se aperfeiçoar os mecanismos de extração de dados da Plataforma Lattes para que estejam aptos a: extrair metadados completos de todas as tipologias de produções bibliográficas, possibilitando análises em publicações preteridas por algumas áreas das Ciências Humanas e artísticas; e, coletar dados estruturados de projetos de pesquisa e dados completos dos pesquisadores (incluindo filiação), no intuito de viabilizar estudos de colaboração institucional e financiamentos de pesquisa. 
Artigo recebido em 06/08/20I8 e aceito para publicação em I0/09/20। 8

\section{ANALYSIS OF THE COMMUNITIES OF BRAZILIAN RESEARCHERS IN THE AREA OF PHILOSOPHY: a study based on the juxtaposition between the data of the Lattes Platform and Web of Science (2007-2016)}

ABSTRACT Considers whether there are different groups of Brazilian researchers of Philosophy in the the intersection between the records of the Lattes Database (LD) and Web of Science (WoS) about the habits of publication. The universe included research curricula 6,060 active in Philosophy, which drew 43,345 papers published between 2007 to 2016, of these, I,657 are indexed in the WoS. The $L D$ data were extracted with the ScriptLattes. Packages used in $R$ programming language to identify the languages of the papers and themes ("Topic Modeling"). To generate graphs of co-authoring it took the Gephi. This study identified two distinct populations: one that works and produces mainly on Philosophy or themes related to the humanities and social sciences (Most of the curricula of researchers) and another whose activities and scientific production are focused in Life Sciences (curricula of intersection), however with interdisciplinary focused bioethical and epistemological studies. The results indicate an average productivity increased in the second half of the decade to both bases. The Portuguese language prevails in LD with 89\%, while the English language dominates in WoS with $75.72 \%$. The journal core of the $L D$ focuses on the area of Philosophy while in WoS predominate Life sciences. The same occurs in thematic maps. There is compatibility between thematic topic maps and coauthor graphs, suggesting good representation of the analyzed communities. It is concluded that the intersection of data becomes visible underlying patterns of publication habits, imperceptible in the traditional methodological strategies.

Keywords: Bibliometric indicators. Brazilian researchers of Philosophy. Humanities. Publication habits.

\section{REFERÊNCIAS}

ARCHAMBAULT, E.; LARIVIERE, V. International social science council, world social sciences report: knowledge divides. Paris: UNESCO, 2010.

BLEI, D.M.; NG, A.Y.; JORDAN, M.I. Latent Dirichlet Allocation. Journal Of Machine Learning Research, Columbia, v. 3, p.993-1022, 2003.

BONACCORSI, A. Peer Review in Social Sciences and Humanities: Addressing the Interpretation of Quality Criteria. In: BONACCORSI, A. (Org.). The Evaluation of Research in Social Sciences and Humanities: Lessons from the Italian Experience. New York: Springer International Publishing, 2018. p. 71-101.

BORREGO, Á.; URBANO, C. La evaluación de revistas científicas en ciencias sociales y humanidades.Información, Cultura y Sociedad, Buenos Aires, n. 14, p.11-27, 2006.
COLLAZO-REYES, F. Growth of the number of indexed journals of Latin America and the Caribbean: the effect on the impact of each country. Scientometrics, [s.1.], v. 98, n. 1, p.197209, 15 maio 2013.

FINKENSTAEDT, T. Measuring research performance in the humanities. Scientometrics, Budapest, v. 19, n. 5-6, p.409-417, 1990.

FRANSSEN, T.; WOUTERS, P. Science and its significant other: Representing the humanities in bibliometric scholarship. 2017. Disponível em: <https://arxiv.org/ftp/arxiv/ papers/1710/1710.04004.pdf $>$. Acesso em: 25 jun. 2018.

GLANZEL, W.; SCHUBERT, A. A new classification scheme of science fields and subfields designed for scientometric evaluation purpose. Scientometrics, Budapest, v.56, n. 3, 2003, p. 357-367. 
IRIBARREN-MAESTRO, I.; LASCURAINSÁNCHEZ, M. L.; SANZ-CASADO, E. The Use of Bibliometric Techniques in Evaluating Social Sciences and Humanities. In: ASTROM,

FREDRIK et al (Org.).Celebrating Scholarly Communication Studies: a Festschrift for Olle Persson at his 60th Birthday. Lund: ISSI, 2009. p. 25-37.

HEMLIN, S.; GUSTAFSSON, M. Research production in the arts and humanities a questionnaire study of factors influencing research performance. Scientometrics, Budapest, v. 37, n. 3, p.417-432, 1996.

HICKS, Diana et al. Bibliometrics: The Leiden Manifesto for research metrics. Nature, [s. L.], v. 520, n. 7548, p.1-3, 22 abr. 2015.

HUANG, Mu-hsuan; CHANG, Yu-wei. Characteristics of research output in social sciences and humanities: From a research evaluation perspective. Journal Of The American Society For Information Science And Technology, [s.1.], v. 59, n. 11, p.1819-1828, set. 2008.

LETA, J. Brazilian growth in the mainstream science: The role of human resources and national journals. Journal Of Scientometric Research, New Delhi, v. 1, n. 1, p.44-52, 2012.

MENA-CHALCO, J. P. e R. M. Cesar-Jr. Prospecção de dados acadêmicos de currículos Lattes através de scriptLattes. Capítulo do livro Bibliometria e Cientometria: reflexões teóricas e interfaces São Carlos: Pedro \& João, páginas 109128, 2013.

NIKITA, M. Tuning of the Latent Dirichlet Allocation Models Parameters. 2016. Package. Disponível em: <https://cran.r-project.org/ web/packages/ldatuning/ldatuning.pdf $>$. Acesso em: 24 out. 2016.

NEDERHOF, A. J. et al. Assessing the usefulness of bibliometric indicators for the humanities and the social and behavioural sciences: a comparative study. Scientometrics, Budapest, v. 15, n. 5, p.423-435, 1989.

NEDERHOF, A. J. Bibliometric monitoring of research performance in the Social Sciences and the Humanities: A Review. Scientometrics, [s.l.], v. 66, n. 1, p.81-100, jan. 2006.

OCHSNER, M.; HUG, S. E.; DANIEL, H.D. Research Assessment in the Humanities: Introduction. Research Assessment In The Humanities, [s.1.], p.1-10, 2016.
OCHSNER, M.; HUG, S.; GALLERON, I. The future of research assessment in the humanities: bottom-up assessment procedures. Palgrave Communications, [s.1.], v. 3, p.1-12, 21 mar. 2017.

OSSENBLOK, T. L. B.; ENGELS, T. C. E.; SIVERTSEN, G.. The representation of the social sciences and humanities in the Web of Science--a comparison of publication patterns and incentive structures in Flanders and Norway (2005-9). Research Evaluation, [s.l.], v. 21, n. 4, p.280-290, 8 set. 2012.

PACKER, A. La visibilidad de las revistas de Brasil [online]. SciELO en Perspectiva, 2014 [viewed 22 May 2018]. Available from: https:// blog.scielo.org/es/2014/11/05/la-visibilidad-delas-revistas-en-brasil/

PORTO, D. Qualidade \& finalidade: características da bioética brasileira. Revista Bioética, [s.1.], v. 25, n. 3, p.443-453, dez. 2017.

REALE, E. et al. A review of literature on evaluating the scientific, social and political impact of social sciences and humanities research. Research Evaluation, [s.1.], p.1-11, 18 jul. 2017. Oxford University Press (OUP). http:/ / dx.doi.org/10.1093/reseval/rvx025.

SANTOS, L. M. P. et al. Fulfillment of the Brazilian Agenda of Priorities in Health Research. Health Research Policy And Systems, [s.l.], v. 9, n. 1, p.1-15, 31 ago. 2011.

SANZ-CASADO, E.; LASCURAIN-SÁNCHEZ, M. L.; IRIBARREN-MAESTRO, I. Luces y sombras en la evaluación de la investigación en ciencias sociales y humanidades. In: IBARRA, A.; CASTRO, J.; BARRENECHEA, J. (Org.).La evaluación de la actividad científica en ciencias sociales y humanidades. Bilbao: Universidad del Pais Vasco, 2007. p. 15-32.

SIVERTSEN, G. Patterns of internationalization and criteria for research assessment in the social sciences and humanities. Scientometrics, [s.l.], v. 107, n. 2, p.357-368, 2 fev. 2016.

THELWALL, M.; DELGADO, M.M. Arts and humanities research evaluation: no metrics please, just data. Journal of Documentation, [s.1.], v. 71, n. 4, p.817-833, 13 jul. 2015.

VAN LEEUWEN, T. Bibliometric research evaluations, Web of Science and the Social Sciences and Humanities: a problematic. Bibliometrie-Praxis und Forschung, Regensburg, v. 2, p.1-8, 2013. 